\title{
Feminismo e Arte Contemporânea: A transfiguração e a (re)ssignificação de poéticas. ${ }^{1}$
}

\author{
Femenismo y Arte Contemporánea: La transfiguración y la (re) \\ ssignificación de poéticas.
}

\author{
Feminism and Contemporary Art: The transfiguration and (re) \\ signification of poetics.
}

\author{
Williana da Silva Maciel $^{2}$
}

\begin{abstract}
Resumo
O presente trabalho objetiva-se investigar a relação de gênero e a produção contemporânea nas Artes Visuais. Apresentaremos conceitos do movimento feminista e seus respectivos impactos na Arte Contemporânea Latina Americana. O surgimento do movimento feminista com suas reivindicações de igualdade de gênero, direitos e participações das mulheres nas esferas políticas e sociais influenciou e influencia as mulheres artistas a falarem e representarem nas suas obras sobre as questões que as atravessam. Sobre essa trajetória, pensaremos a produção artística contemporânea de algumas mulheres latinas que buscam problematizar conceitos de gênero, sexualidade e violência. Uma imagem inferiorizada do ser feminino foi construída dentro do pensamento de todo o ocidente. As mulheres foram distanciadas ao longo da história de todas as atividades ligadas ao intelecto, ou seja, essas atividades do intelecto e de ordem pública eram somente associadas ao masculino. A história da arte ocidental estruturada por uma lógica machista, sexista e misógina colocou as mulheres no lugar de objeto dentro da própria arte. As mulheres sempre foram representadas artisticamente para atender os desejos e os critérios masculinos, uma relação desigual se estabeleceu em nossa cultura. $\mathrm{O}$ feminismo afetou o movimento artístico no final do século XX e começo do século XXI, diversificado e ampliando poéticas, teorias e práticas artísticas. As discussões contemporâneas latinas a respeito da arte fecundam debates políticos de emancipação dos direitos das mulheres, questionam as narrativas e a historiografia hegemônica das Artes Visuais e pensam novas perspectivas de raça, gênero e classe. As reflexões dão ênfase à inserção da produção de mulheres artistas e como essas produções estão situadas em um espaço de resistência e resiliência. A trajetória influente do feminismo na década de 1960 deixa marcas politicas na arte, as poéticas insubordinadas dessas artistas dão novas formas e sentidos à história da arte.
\end{abstract}

Palavras-Chave: Arte Contemporânea; América Latina; Feminismo; História da Arte.

\section{Resumen}

El presente trabajo se pretende investigar la relación de género y la producción contemporánea en las Artes Visuales. Presentaremos conceptos del movimiento feminista y sus respectivos impactos en el Arte Contemporáneo Latinoamericano. El surgimiento del movimiento feminista con sus reivindicaciones de igualdad de género, derechos y participaciones de las mujeres en las esferas políticas y sociales influenció e influenció a las mujeres artistas a hablar y representar en sus obras sobre las cuestiones que las atravesan. Sobre esta trayectoria, pensaremos la producción artística contemporánea de algunas mujeres latinas que buscan

\footnotetext{
${ }^{1}$ Artigo apresentado no Simpósio Temático (ST 10 - Jovens Pesquisadores Latino-americanos (Graduandos) Temática Livre) durante o II Seminário Latino-Americano de Estudos em Cultura - SEMLACult em Foz do Iguaçu/PR, Brasil, 2018.

${ }^{2}$ Graduanda em Artes Visuais; Universidade Regional do Cariri - URCA; Juazeiro do Norte, Ceará, Brasil; williaanasilva@hotmail.com.
} 
problematizar conceptos de género, sexualidad y violencia. Una imagen inferiorizada del ser femenino fue construida dentro del pensamiento de todo el occidente. Las mujeres fueron distanciadas a lo largo de la historia de todas las actividades ligadas al intelecto, o sea, esas actividades del intelecto y de orden público eran solamente asociadas al masculino. La historia del arte occidental estructurada por una lógica machista, sexista y misógina colocó a las mujeres en lugar de objeto dentro del propio arte. Las mujeres siempre fueron representadas artísticamente para atender los deseos y los criterios masculinos, una relación desigual se estableció en nuestra cultura. El feminismo afectó el movimiento artístico a finales del siglo XX y comienzos del siglo XXI, diversificado y ampliando poéticas, teorías y prácticas artísticas. Las discusiones contemporáneas latinas acerca del arte fecundan debates políticos de emancipación de los derechos de las mujeres, cuestionan las narrativas y la historiografía hegemónica de las Artes Visuales y piensan nuevas perspectivas de raza, género y clase. Las reflexiones dan énfasis a la inserción de la producción de mujeres artistas y cómo esas producciones están situadas en un espacio de resistencia y resiliencia. La trayectoria influyente del feminismo en la década de 1960 deja marcas políticas en el arte, las poéticas insubordinadas de esos artistas dan nuevas formas y sentidos a la historia del arte.

Palabras claves: Arte Contemporaneo; América Latina; feminismo; Historia del Arte.

\begin{abstract}
The present work aims to investigate a relation of gender and a contemporary production in the Visual Arts. . Feminist ideas and their respective impacts on contemporary Latin American art. The movement of the feminist movement with the same characteristics of gender, rights and participation of women with regard to socially influenced policies and influence women artists to speak and represent in their works on the issues that cross them. About this trajectory, we will consider a contemporary artistic production of some Latin women who seek to problematize concepts of gender, sexuality and violence. An inferior image of the human being was built within the thinking of the whole West. Women have been distanced throughout history from all activities related to the intellect, that is, those activities of intelligence and expression were made only to man. Sexuality is a structured technique for a sexist, sexist and misogynist woman placed as a woman instead of an object within the art itself. Women have always been artistically represented for meeting male desires and criteria, an unequal relationship, and our culture. Feminism affects the movement in the late twentieth century and begins the twenty-first century, diversifying and expanding the poetics, theories and artistic practices. Contemporary discus- sions on women and debates debate women's rights to emancipate women's rights, question how the hegemonic narratives and histories of the visual arts, and the new perspectives of race, gender, and class. The reflections are fundamental for the production of women and artists and the productions are situated in an area of resistance and resilience. The influential trajectory of feminism in the 1960s leaves political marks in art, such as digital insidia and art literature.
\end{abstract}

Keywords: Contemporary Art; Latin America; Feminism; History of Art.

\title{
Introdução
}

A produção artística durante toda a humanidade ocidental foi majoritariamente dominada por homens. Nas últimas décadas surgiram debates a respeito da história da arte e como as questões de gênero são essenciais quando pensamos a construção da mesma. Questiona-se, a crença social negadora dos espaços artísticos para as mulheres. O fator sexo estruturou, legitimou e delimitou quem poderia ocupar determinados espaços e outros não. Os discursos foram sendo construídos através de uma ótica e uma perspectiva masculina distorcendo o ser mulher e dando como característica ao feminino, um individuo passivo e insuficiente para desenvolver um domínio pleno sobre as coisas e sobre si. Tornando assim, a imagem e a representação da mulher como um individuo inativo, inacabado e passivo. A 
história da arte foi fragmentada por uma ausência pública e epistêmica de suas mulheres, negou-se todo o legado do pensamento e da produção artística feminina.

A mulher foi limitada ao espaço da casa e da reprodução, o ambiente "natural" delas estava delimitado e destinado ao lar, mas mesmo com todo esse pertencimento de serviços domésticos e manuais muitas mulheres aprendiam e produziram artisticamente. Suas produções não foram reconhecidas e difundidas por questões culturais e políticas, entretanto, modificar o fluxo das interpretações e resgatar a produção epistêmica e artística sob uma nova ótica dentro de uma estrutura e uma história dominante pelo gênero masculino é possibilitar ao individuo feminino contemporâneo uma representatividade no fazer e no conhecimento artístico.

Na contemporaneidade a hegemonia artística é vista como um problema enorme, pois ela não leva em consideração aspectos importantes como o de raça, classe, gênero e sexualidade. A invisibilidade e o silenciamento das mulheres ocorreram na maioria do mundo. O patriarcado tinha como função e sustentação de si, a inferiorização social das mulheres e daquilo que se aproximasse com o feminino. A América Latina assim como em quase todo o Ocidente permanece sobre uma cultura sexista e misógina, a colonização nas Américas deixaram marcas profundas que ainda hoje no século XXI não foram superadas. O movimento feminista latino através de muita luta possibilitou conquistas importantes para as mulheres e para toda a humanidade.

$\mathrm{Na}$ esfera artística as mulheres começaram a se empoderarem justamente com suas produções e começaram a representarem e a materializarem em suas obras coisas que as atravessavam enquanto mulheres. $\mathrm{O}$ artivismo enquanto prática surge para essas mulheres antes mesmo do conceito postulado. As narrativas divergentes e não-dominantes começaram adentrar e questionar a história da arte, e as mulheres da América Latina começam a circunscrever contra discursos e contra-narrativas visuais que não é a do homem branco, cisgênero, rico e privilegiado.

\section{ARTE E POLITICA: CORPOS FEMININOS RESISTENTES E GERADORES DE NOVOS SENTIDOS}

Com a expansão do movimento feminista nos anos de 1960 pensamentos de emancipação feminina começaram adentrar vários espaços e um deles foi o meio artísticos. As mulheres artistas começaram a configurar e reconfigurar em suas obras questões que não 
passavam despercebidas a seus corpos. A violência, o machismo e o racismo são estruturas que compõe a sociedade Ocidental e as mulheres são os sujeitos que estão na linha de frente sofrendo todas essas mazelas. A arte é politica quando pensamos na necessidade de se discutir questões que são sobre existência, sobre vida, sobre permanência. A arte não é distante da vida, ela é a própria vida em acontecimento.

No século XX e XXI o feminismo e a arte não andam separados, eles se integram em uma mesma consciência de avanços sociais e políticos. Ana Mendieta (1948 - 1985) foi uma artista de grande importância para a arte contemporânea latina americana, nasceu em Cuba e tem sua obra marcada por sua autobiografia. Seu processo e sua poiéses incluem questões feministas, de violência, morte, vida, existência, permanência. Ela nos diz que "é crucial para mim ser parte de todos os meus trabalhos de arte. Como resultado de minha participação, minha visão torna-se realidade e parte das minhas experiências". Mendieta tinha uma relação espiritual com seu trabalho que ia de encontro com a natureza às conexões corporais. A crueza do corpo transfigurado nos desperta para a sensibilidade e a visibilidade do incomodo, como é o caso de sua obra Rape Scene, 1973.
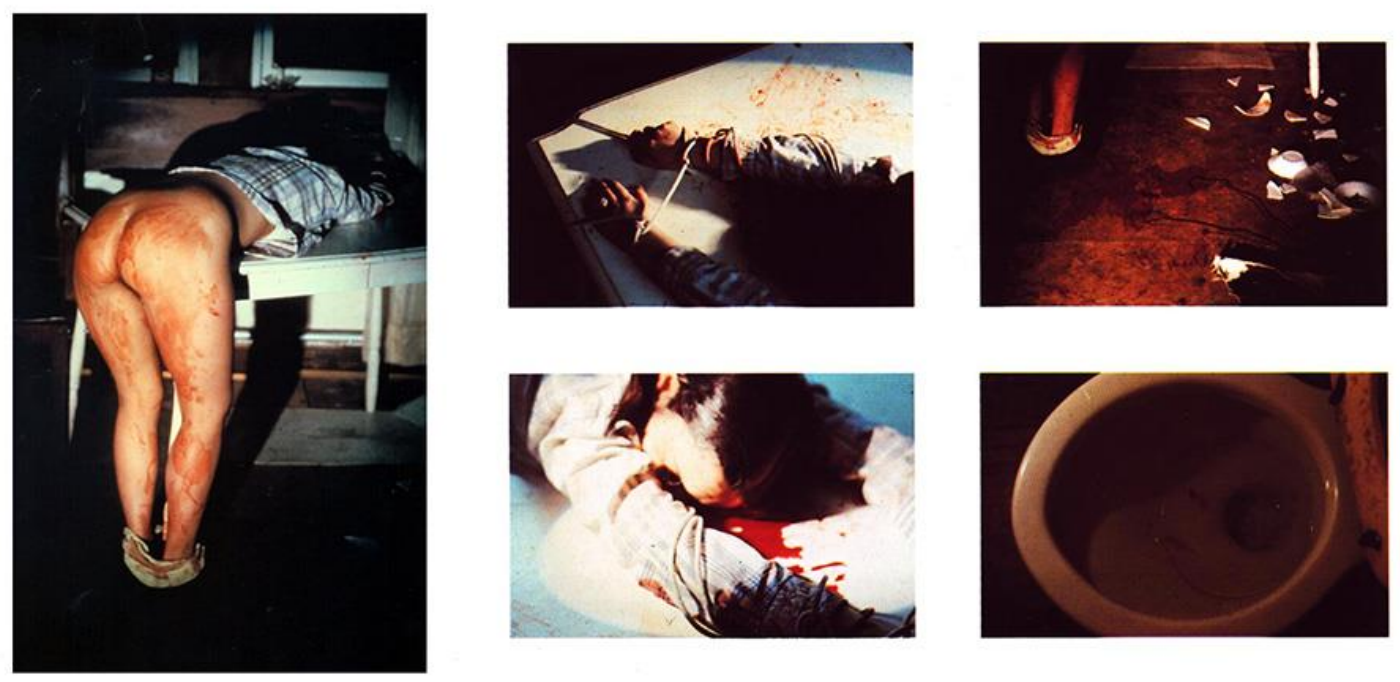

Figura 1 - Rape Scene (1973) Fonte: https://thestereoscopiceye.files.wordpress.com/2013/10/anamedietarape.jpg

A performance intitulada Rape Scene ocorreu em seu apartamento no qual Ana ficava seminua sobre uma mesa durante horas. Tinha sangue escorrendo entre suas pernas e uma cena de violência profunda era marcada dentro de sua própria residência. A ação foi executada pela artista após seu impacto com o caso de uma colega da Universidade de Iowa 
que foi estuprada e morta. Ana criou e recriou a violenta cena do crime e o seu corpo silencioso e estático chegava como um grito de denuncia.

Márcia Pinheiro de Oliveira, Márcia X (1959- 2005) é uma artista Brasileira do Rio de Janeiro que busca explorar em seus trabalhos a relação do sexo e da infância. Ela transforma objetos pornográficos em brinquedos infantis, se aproxima do consumo, da religião, do erotismo e dos valores socialmente construídos em torno do gênero e da sexualidade. Se apropria de objetos e ressignifica seus conceitos. Foi assim que surgiu o trabalho Fábrica Fallus (1992- 2004) que nada mais é do que objetos de estimulação sexual retirado de sua convenção social e transformado em objetos impregnados de ambiguidades.

\footnotetext{
A Fábrica Fallus é metonímia do mundo: uma maquinaria que não para de produzir ícones do desejo, de adaptar os "produtos" a toda sorte de gostos, de recriar e multiplicar o poder do falo. Márcia X volta seu olhar mordaz ao patriarcado, ironizando a obsessão com a sexualidade que caracteriza a sociedade contemporânea, por meio da fabricação de pênis em série. (TVARDOVSKAS, Luana Saturnino, p. 58).
}

Nossa sociedade é muito masculinizada, tudo que remete ao sujeito homem é reafirmado em um sentindo "' legitimador" de crenças e verdades. O patriarcado constrói e da sustentabilidade a liberdade do homem, nós vivemos em uma sociedade machista no qual o sujeito mulher é inferiorizado e silenciado a todo instante. Márcia X com seu trabalho Fábrica Fallus nos aponta para a ridicularização e ironização de uma sociedade que se pauta apenas em atender os desejos masculinos, tornando-se fálica a todo custo. 

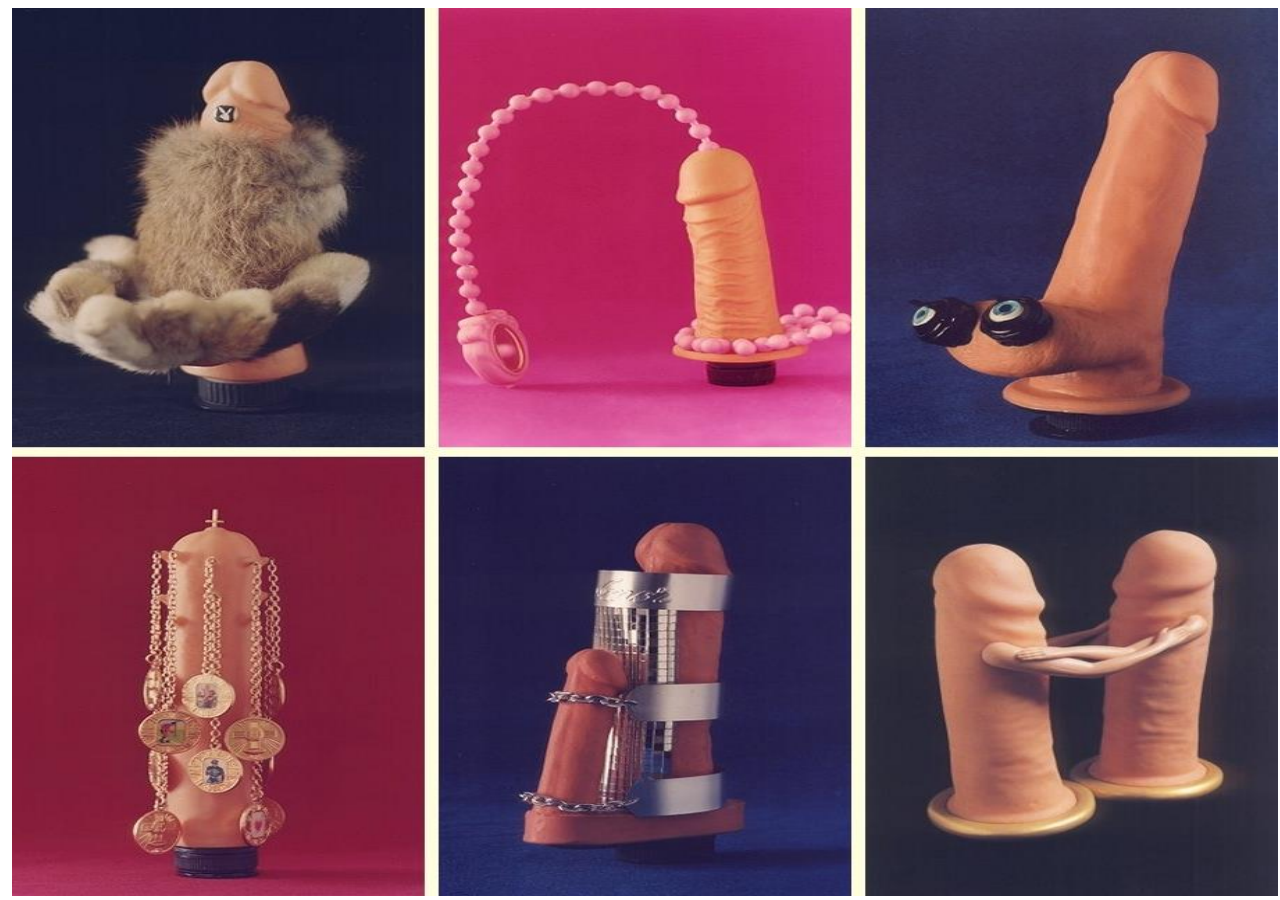

Figura 2 - A Fábrica de Fallus (1973) Fonte: http://marciax.art.br/mxObras.asp?sMenu=1\&sTipo=1

Os pênis de borracha são decorados de maneira alegórica com artigos femininos e religiosos, mostrando-nos de maneira simbólica como a moral religiosa e o feminino estão inseridos para a sustentação e a fragilidade da sexualidade masculina. Desestabilizar lugares e símbolos masculinizados é importante para abertura de novos espaços e de outros gêneros que não é o masculino. A cultura do sexo no Brasil tem que ser questionada e trabalhos como o de Márcia X tem esse poder de estratégias politica-culturais de enfrentamento dos mitos e tabus.

Sandra Eleta (1942) é uma artista do Panamá e tem diversos trabalhos com fotografias, ela se deleita sobre as perspectivas afro-coloniais e os povos indígenas que ficam próximo ao Atlântico. Explora o cotidiano dos povos e as materializam através de cliques fotográficos. A fotografia abaixo faz parte da série A servidão, Panamá, 1977. Ela explora o ambiente doméstico no qual a maioria das mulheres é submetida a está. Como empregada, como mãe, como "dona da casa", as tarefas de casa estão sujeitadas ao feminino e o lar é um lugar violento e cheio de contradições para as mulheres. O machismo começa dentro da própria casa por normas tradicionais e funções de gênero a serem desempenhadas. $O$ ambiente doméstico é um lugar romantizado, mas em sua essência é onde mais se acontecem opressões, abusos e violências. O feminismo tem que se fazer enquanto discurso, mas deve ser acompanhado da prática. Nós mulheres, se caminharmos juntas, caminhamos melhor. 


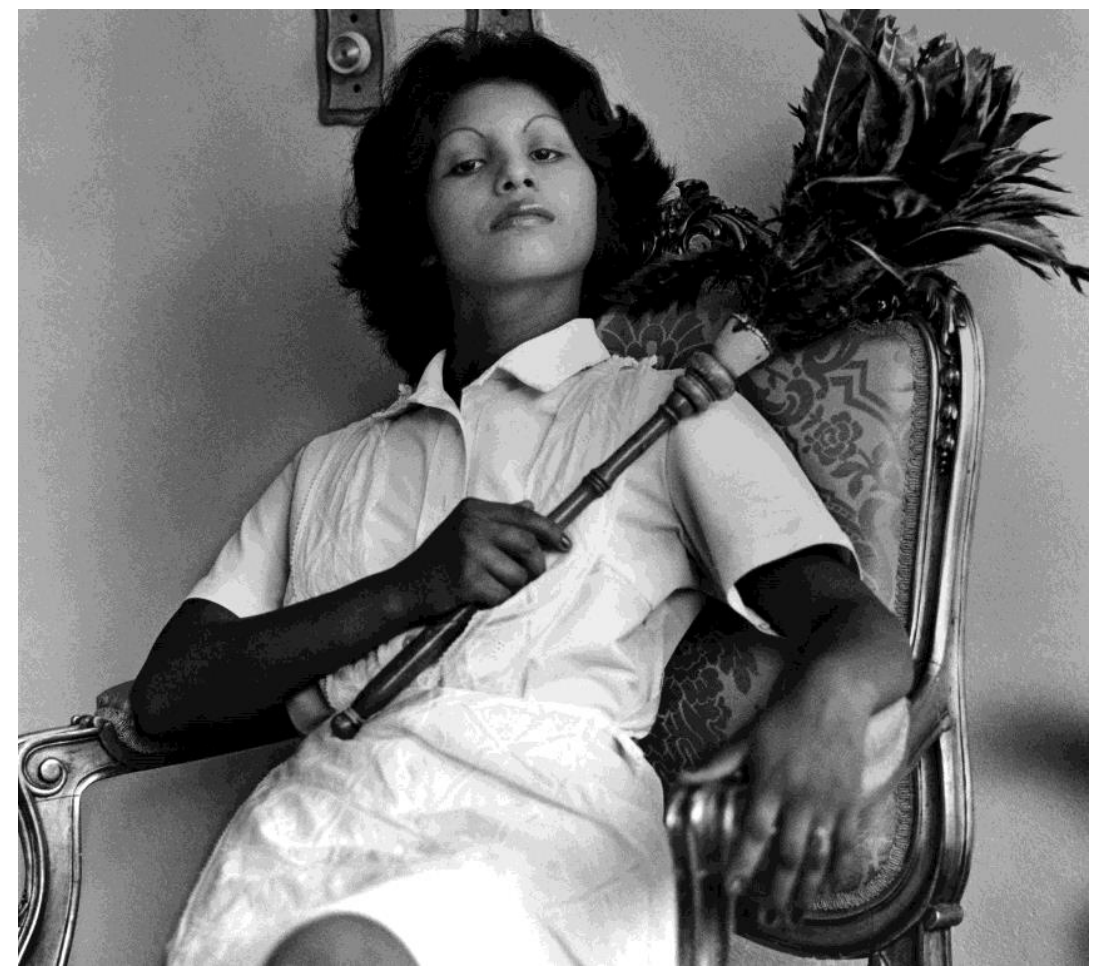

Figura 3 - Serie A Servidão (1977) Fonte: http://www.sandraeleta.com/es/

\section{Conclusões}

Mulheres produtoras de arte são importantes na humanidade para não termos uma visão única e exclusiva do que é arte. Muitas mulheres destruíram fronteiras e alargaram territórios com suas produções, acreditamos que arte faz parte e é de todos os seres humanos. Construir novas narrativas é preciso, questionar o patriarcado e o sexismo também. A arte contemporânea latina nos possibilita outros olhares e afetações. O artivisto não é questão de querer, a política e arte estão para o ser humano como o ser humano está para a vida. Transgredir e traçar novos rumos para a história da arte é nos libertar e nos emancipar enquanto artistas. A igualdade entre os gêneros prevê uma democracia de existência e a gestação de uma arte feminista ou de uma arte que tem propósitos de falar sobre mulheres abre espaços na sociedade para tantas outras- outras mulheres, outros gêneros, outros, outras, outris. Os nossos corpos tem que ser deixados de ser considerados objetos para serem sujeitos, corpos produtores de arte, corpos produtores de vida. Escrevo esse trabalho em memória de todas artistas que já foram e de todas que estarão por vir. Por nós e por todas. A América Latina tem força e a revolução feminista começará por aqui. 


\section{Referências}

Ana Mendieta Untitled (Rape Scene) 1973: Disponível em: https://thestereoscopiceye.files.wordpress.com/2013/10/anamedietarape.jpg Acesso em: 26 julho 2018.

COURI, Aline. O FEMINISMO EM ANA MENDIETA. Rio de Janeiro, 2017. Disponível em: $\quad$ https://topicoespecialvideoarte.wordpress.com/2016/02/17/o-feminismo-em-anamendieta/. Acesso em: 26 julho 2018.

FRANCISCHETTI, Paula. Algumas questões sobre o feminino e a arte de Ana Mendieta. São Paulo, 2009. Disponível em: http://citrus.uspnet.usp.br/estetica/index.php/anteriores/78revista-1/9-2009-1-art6. Acesso em: 26 julho 2018

GERMANO, Beta. As artistas feministas que estão agitando o mercado de arte. Disponível em: https://casavogue.globo.com/LazerCultura/noticia/2018/03/artistas-feministas-que-estao-agitando-omercado-de-arte.html. Acesso em: 26 julho 2018.

TVARDOVSKAS, Luana Saturnino. Figurações feministas na arte contemporânea: Márcia X, Fernanda Magalhães e Rosângela Rennó-Campinas. SP : [s. n.], 2008.

Site da Artista Visual Sandra Eleta. Disponível em: http://www.sandraeleta.com/es/. Acesso em: 26 julho 2018.

Site da Artista Visual Márcia X. Disponível em: http://marciax.art.br/. Acesso em: 26 julho 2018. 